\title{
Analysis of PISA data on the effect of student's parents on Math Anxiety in Spanish students
}

\author{
David Gutiérrez-Rubio, Alexander Maz-Machado, Carmen León-Mantero \\ Facultad de Ciencias de la Educación, Universidad de Córdoba \\ dgrubio@uco.es,ma1mamaa@uco.es,cmleon@uco.es \\ María José Madrid-Martín \\ Universidad Pontificia de Salamanca \\ mariajosemadrid6@gmail.com
}

\begin{abstract}
In this work we present a descriptive study of the effects that the schooling level of both parents (mother and father) may cause in the levels of Math Anxiety in Spanish students from secondary education. We study the effects separately for male and female students, and native, first, and second generation of immigrants. Results show a slightly bigger influence of the mother over the father. For higher ISCED levels, native and second generation immigrants have same behavior, while for lower levels natives have less anxiety. In families where the mother has a higher ISCED level than the father, female students native and second generation immigrants have more Math Anxiety, whereas the opposite occurs in male students.
\end{abstract}

Indexing terms/Keywords:Keywords are your own designated keywords which can be used for easy location of the manuscript using any search engines.

Subject Classification:Math Anxiety,Secondary Education, PISA report

Type (Method/Approach):Exploratory quantitative study

Introduction:The study of attitudinal variables in mathematics is a subject that has been gaining weight in recent years. Multiple studies emphasize their influence on the academic performance of the students, as well as in their future academic trajectory [5]. Given its predictive nature it seems worthwhile to analyse which variables of the student's environment can influence these attitudinal components.

In this work we focus on Math Anxiety, which can be defined as the absence of comfort that someone might experience when required to perform a mathematical task [14]. Mathematical Anxiety usually influences negatively on the academic results and tends to be higher in female students rather than in male ones [4]. This result is replicated in multiple studies, being one of the most recent the PISA 2012 report [9], where this gap exists even in countries where math performance in female students equals to the male ones.

Works such as [6] show a negative correlation between levels of mathematical anxiety and performance in mathematics in Western European countries such as Finland, Netherlands or Switzerland, but not in Asian countries like Korea or Japan.

Besides its influence on the academic performance, Math Anxiety can be an important factor when students have to decide their choose of careers as those with high levels of anxiety tend to avoid studies with math contents [10].

There is also a direct relation between the Math Anxiety levels and the methodology used, as more anxious students tend to take an instrumental approach rather than a relational one $[2,8]$. Moreover, students with 
high level of anxiety tend to avoid using advanced problem solving, and this effect is strongest for students with higher working memory capacity [11].

Math Anxiety can be transmitted from parents to sons, so that when the parents (or primary caretakers) exhibit anxiety when helping with math homework (and they provide this help often), their children have significantly more anxiety than the rest [7].

The purpose of this work is to study the effect of the schooling level of parents over the Math Anxiety of their children, and if these effects depends on the gender or native or immigrant status of the student.

\section{Materials and Methods}

We propose a quantitative, descriptive and exploratory study from the data of PISA 2012 survey. We choose this year as the PISA 2015 did not include the Math Anxiety in its questions. The sample consists of 25313 students from the Spain sample, all with age 15 years. Since Math Anxiety shows differences between genders, the statistics are computed separately for female and male students. We also considered if the student was native, first generation immigrant or second generation immigrant. In this sense, we define first generation as those who were born outside Spanish territory, whereas second generation corresponds to students born in Spanish territory and at least one of the parents is immigrant. Although this last definition doesn't match the one used by PISA, it is convenient as it includes the case of mixed couples, which represents $6.8 \%$ of the sample [1]. Schooling level of the parents is classified according to the ISCED-1997 levels [13]. For simplicity we considered only students with two parents (not monoparental families).

\section{Results and Discussion}

Math Anxiety (ANXMAT) scores from -2.37 to 2.55 in the PISA standardized scale. Female students had a mean of 0.33 whereas male students had 0.02 , which is equivalent to 24.8 points in a percentile scale. An Anova was considered to contrast the effect of the schooling level of mother and father respectively. To analyse the effect of the ISCED level of the mother, we divide the sample in 6 segments (male/female, native/1stGen/2ndGen) and perform an Anova in each of them. In all cases the p-value is 0.00 , so the ISCED of the mother correlates with Math Anxiety of the students. We consider a post-hoc analysis, using the T2 Tamhane Test, comparing the differences of one level with its next one, and checking where are statistically significant differences from one level to the immediately superior. In Table 1 there are denoted with asterisks when a level has this kind of differences with its lower one. In the right column the range of the Math Anxiety is computed.

Highest schooling of mother

\begin{tabular}{|c|c|c|c|c|c|c|c|c|}
\hline & & ISCED1 & ISCED 2 & ISCED 3B, C & ISCED $3 \mathrm{~A}, 4$ & ISCED 5B & ISCED 5A, 6 & Range \\
\hline \multirow{3}{*}{ Female } & Native & * & * & * & * & * & * & 0,43 \\
\hline & $1 \mathrm{Gen}$ & & * & * & & * & * & 0,30 \\
\hline & 2Gen & * & & * & * & * & * & 0,78 \\
\hline \multirow{3}{*}{ Male } & Native & * & & * & * & * & * & 0,56 \\
\hline & $1 \mathrm{Gen}$ & & * & * & * & * & * & 1,78 \\
\hline & 2Gen & * & & & & & * & 0,57 \\
\hline
\end{tabular}


Table 1: Statistically significant changes of Math Anxiety from one level to the next when changing the ISCED of the mother $(p=0.05)$

As we can see form the table, native female students are more sensitive to changes in the schooling level as they experiment significant changes in their Math Anxiety when changing the ISCED level, which is consistent with studies like those from [3]. Male students from the second generation of immigrants, although they have the same range as their native counterparts, exhibit less dependence as they only have significant differences for lower and higher levels of schooling of both parents.

In a more global approach, native females seem to have less dispersion than native males depending on the ISCED of the mother, as the range of females is smaller than the male ones. This situation inverts in the second generation case.

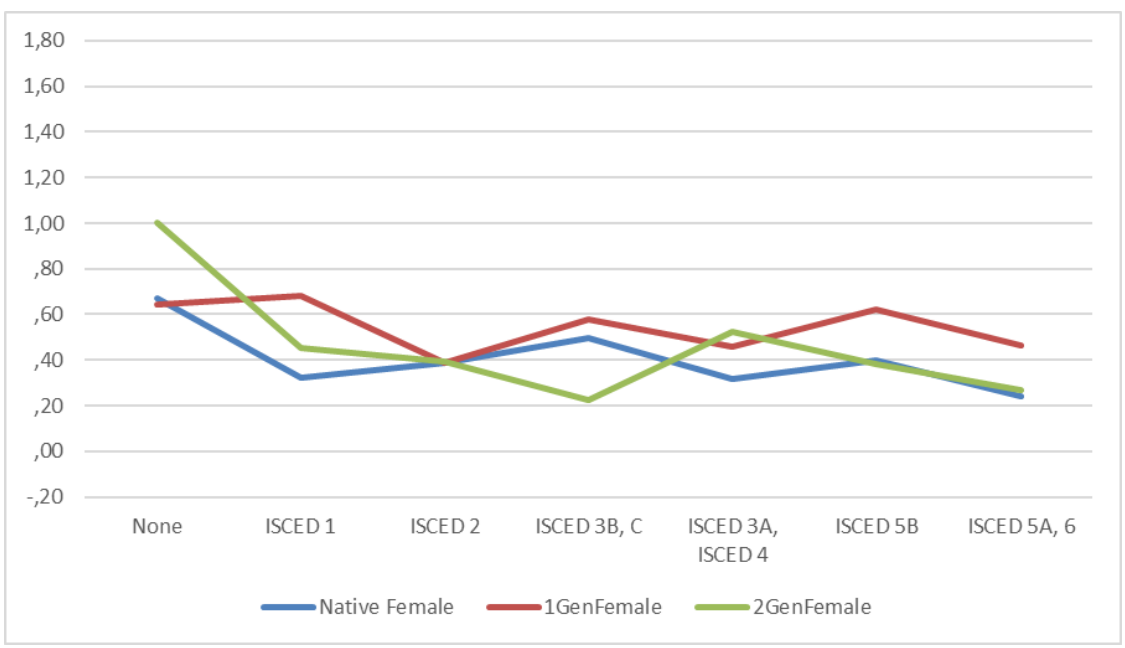

Figure 1: Influence of the ISCED of the mother in Mathematics Anxiety in female students

In figure 1 we represent the mean Math Anxiety of native, first generation and second generation immigrant female students according to the ISCED level of the mother. In the 3 cases, there is a negative gap when passing from None to ISCED 5A, 6 level. The first generation has uniformly more anxiety than the native ones, although this difference is null when the mother has the ISCED 2 level. Native and second generation immigrants have similar levels of Math Anxiety for superior ISCED levels of the mother (ISCED 6B, ISCED 5A, 6).

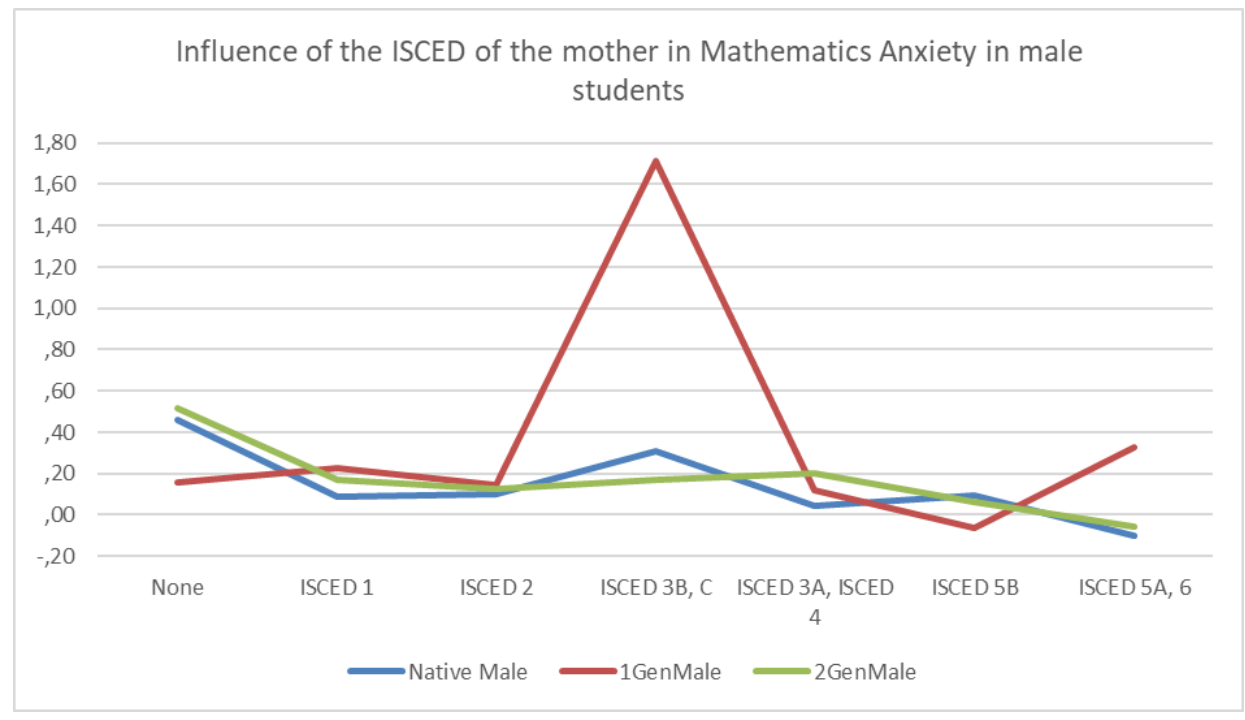


Figure 2: Influence of the ISCED of the mother in Mathematics Anxiety in male students

Figure 2 shows the influence of the mother in male students. The unusual high value draws attention. This is due mostly to an observation with very high Math Anxiety (2.55) and a high weight (105,96 over 136) that has a strong influence in the mean. Eliminating this observation results in a mean of 0.53 , which is a more expected value. Again, high ISCED levels of the mother results in the same levels of Math Anxiety for native and second generation immigrants, whereas the first generation experiments a little increase (which is statistically significant). Also, at ISCED 3B, C level, second generation immigrants seems to have less Math Anxiety than native ones. This difference is statistically significant ( $p$-value 0.018 ).

In order to study the effect of the ISCED level of the father We performed in similar way than the previous case. The Anova gives a p-value of 0.00 in all the 6 segments of the sample (male/female, native/1stGen/2ndGen) which means that the ISCED of the father correlates with the Math Anxiety of the students. In Table 2 we represent similar data than Table 1, using the father's ISCED as a factor.

Highest schooling of father

$\begin{array}{llllll}\text { ISCED1 ISCED } 2 & \text { ISCED 3B, C } & \text { ISCED 3A, } 4 & \text { ISCED 5B } & \text { ISCED 5A, } 6 & \text { Range }\end{array}$

\begin{tabular}{|c|c|c|c|c|c|c|c|c|}
\hline \multirow{3}{*}{ Female } & Native & \multirow[t]{2}{*}{ * } & & * & * & * & * & 0,31 \\
\hline & $1 \mathrm{Gen}$ & & * & * & * & * & & 0,29 \\
\hline & 2Gen & * & * & * & * & * & * & 0,62 \\
\hline & Native & * & * & * & * & * & * & 0,35 \\
\hline Male & $1 \mathrm{Gen}$ & * & * & * & & & & 0,40 \\
\hline & 2Gen & & * & & & & * & 0,67 \\
\hline
\end{tabular}

Table 2: Statistically significant changes of Math Anxiety from one level to the next when changing the ISCED of the father $(p=0.05)$

The mother seems to have more influence than the father as changes in her ISCED level are more inclined to lead to significant differences in Math Anxiety, especially in male students. This difference between parents is also observed in other works like [12]. Again, second generation male students seem to be more reluctant to change from one ISCED level to the next. 


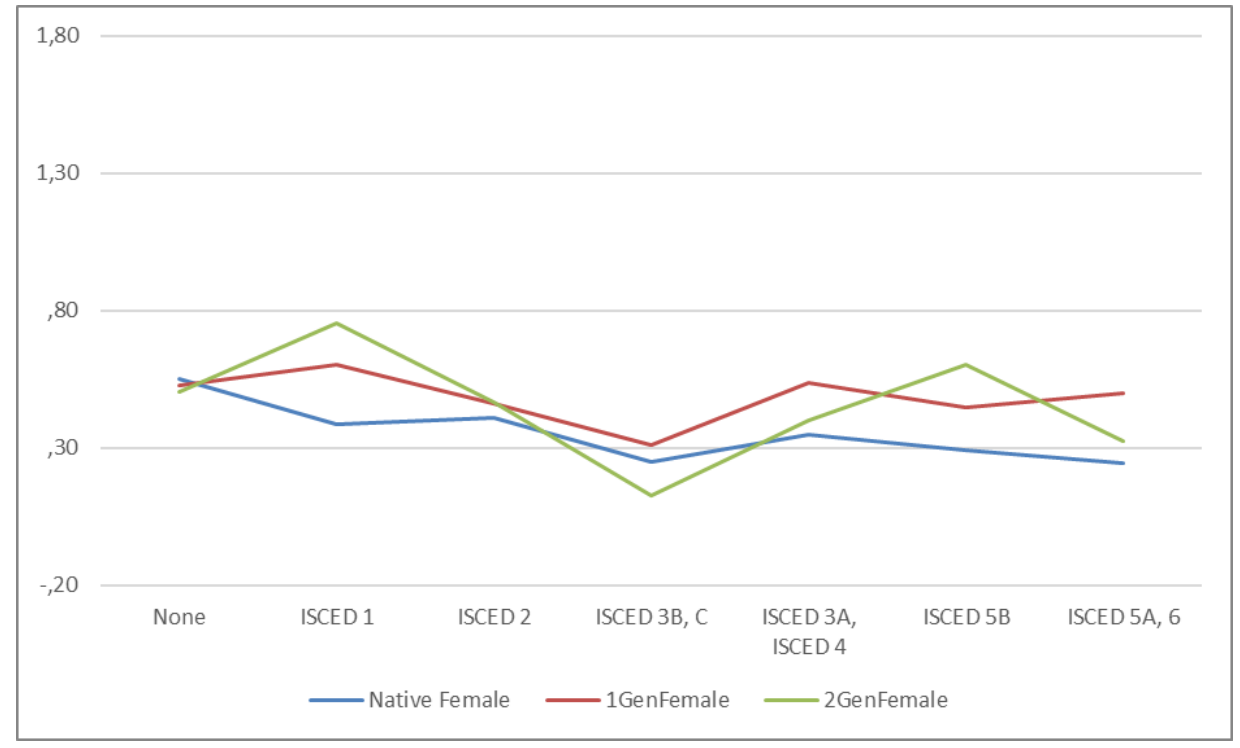

Figure 3: Influence of the ISCED of the father in Mathematics Anxiety in female students

In Figure 3 we can observe that the father's ISCED has a somewhat irregular in female students. ISCED level 3B, $C$ seems to have a peak of minimum anxiety. In this case, second generation has less Math Anxiety than native ones. This difference is statistically significant ( $p$-value 0.026 ), as it happened in the mother's case.

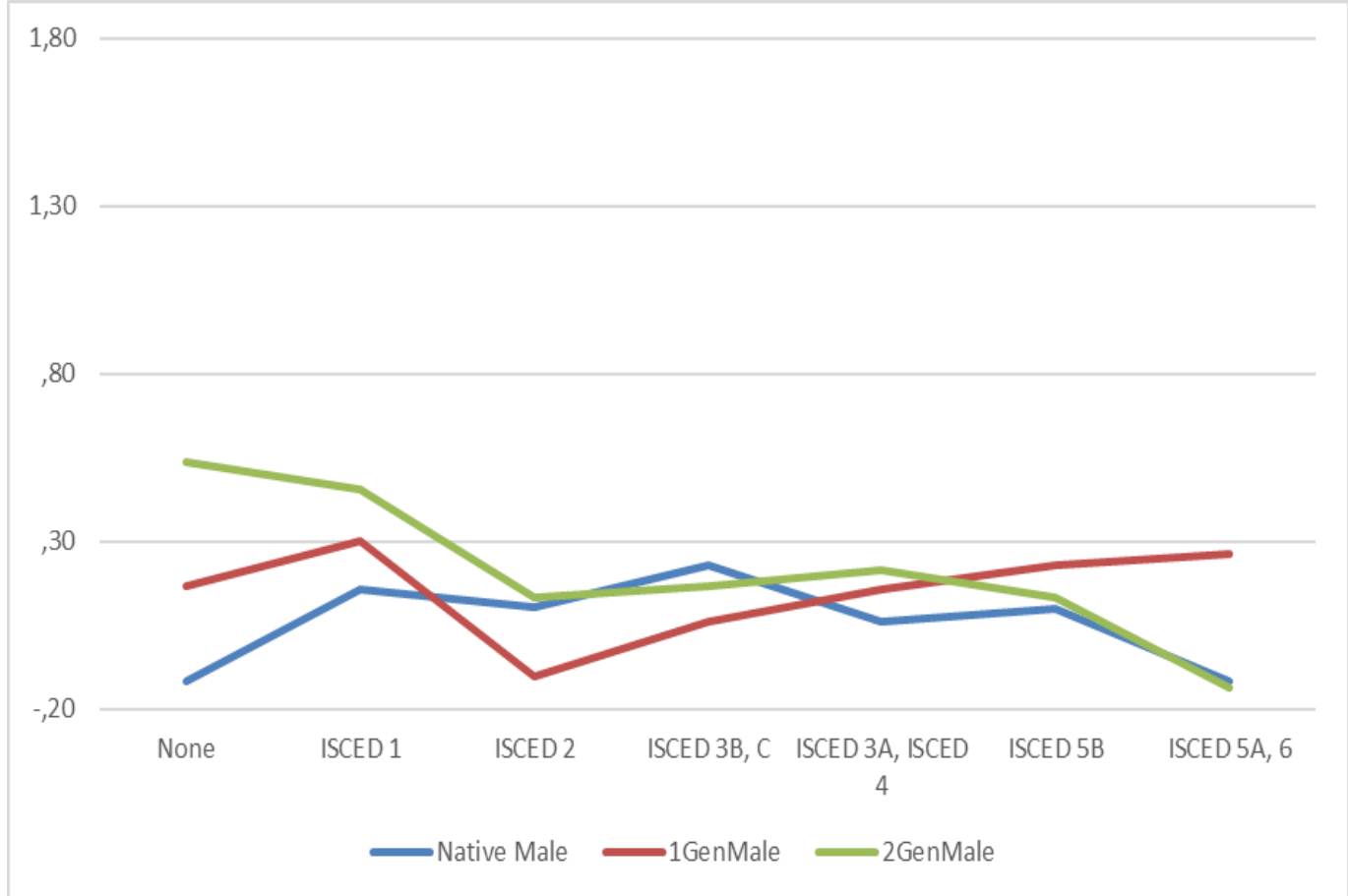

Figure 2: Influence of father in Mathematics Anxiety

In Figure 4, influence of father in male students, in high ISCED levels seems to have a similar effect than the mother's in female students, where native and second generation have similar levels of Math Anxiety. First generation seems to experiment a negative influence from ISCED level 3B onwards, as it also happens in less uniform way in the mother's case. 


\begin{tabular}{ccccc} 
& & $\begin{array}{l}\text { ISCED of } \\
\text { Mother }< \\
\text { ISCED of } \\
\text { Father }\end{array}$ & $\begin{array}{l}\text { ISCED of } \\
\text { Mother }> \\
\text { ISCED of } \\
\text { Father }\end{array}$ & p-value \\
\cline { 2 - 5 } Female & Native & 0,3289 & 0,3494 & 0.00 \\
& 1Gen & 0.4512 & 0.4662 & 0.50 \\
\hline \multirow{2}{*}{ Male } & NGen & 0.5011 & 0.5489 & 0.05 \\
& 2Gen & 0.0981 & 0.0621 & 0.00 \\
& 0.2467 & 0.2179 & 0.22 \\
& & 0.0575 & 0.1942 & 0.00
\end{tabular}

Table 3: Math Anxiety when mother's ISCED is less (resp. bigger) father's one, along with the p-values of mean contrasts.

Regarding the joint effect of mother and father, in Table 3 we show the mean values of Math Anxiety for the 6 segments of the sample divided in 2 groups: those where the ISCED of the mothers is less than the father's one and the opposite. We didn't consider the equal case. We performed a t-test in order to check the equality of the means between these two groups. As we can see, differences are statistically significant for native and second generation immigrants. It is worth noting that superior ISCED levels in the mother respect to the father induces more anxiety in native females (and less in native males) whereas the opposite effect occurs in second generation students, especially in male students, where Math Anxiety increases about 12 points in the percentile scale. It is relevant also that students of first generation from both genders don't show significant differences between the two possible scenarios.

\section{Conclusions}

Mother's ISCED seems to have a slightly bigger influence than father's one in Math Anxiety of students which is consistent with previous studies. Native and second generation immigrant tend to have the same Math Anxiety levels when the mother or father have high ISCED levels (5B, 5A, 6$)$, except for the pair father-female. In this sense, the gap between native and immigrants, when there are obvious causes related to the first generation immigrants like language for example, does still seem to exist in the second generation when the ISCED level of the parents is not high.

Gender stereotypes seem to affect, slightly but statistically significant, to the Math Anxiety when the ISCED level of the mother is superior to the ISCED of the father. In that case, female students (native and 2ndGen) have more Math Anxiety than the opposite case. The inverse effect happens in male students, also native and 2ndGen, where Math Anxiety decreases slightly.

As future lines of research, more attitude variables, like Math Self-Efficacy or Math Attribution Failure should be analysed in order to extend the influence of the schooling level of parents.

\section{ConflictsofInterest}

There are no conflicts of interest concerning this research study 


\section{FundingStatement}

The research was funded only by the authors.

\section{References}

1. Álvarez-Sotomayor, A., Martínez-Cousinou, G., \& Gutiérrez-Rubio, D. (2015). Cuando la segunda generación no se queda atrás: evidencias sobre el rendimiento académico de los hijos de inmigrantes en el caso andaluz. EstudiossobreEducación, 28, 51-78.

2. Clute, P. S. (1984). Mathematics Anxiety, Instructional Method, and Achievement in a Survey Course in College Mathematics. Journal for Research in Mathematics Education, 15(1), 50. https://doi.org/10.2307/748987

3. Engelhard, G. (1990). Math Anxiety, Mother's Education, and the Mathematics Performance of Adolescent Boys and Girls: Evidence from the United States and Thailand. The Journal of Psychology, 124(3), 289-298. https://doi.org/10.1080/00223980.1990.10543224

4. Fennema, E., \& Sherman, J. A. (1976). Fennema-Sherman mathematics attitudes scales: Instruments designed to measure attitudes toward the learning of mathematics by females and males. Journal for research in Mathematics Education, 7(5), 324-326.

5. Hackett, G., \& Betz, N. E. (1989). An exploration of the mathematics self-efficacy/mathematics performance correspondence. Journal for research in Mathematics Education, 261-273.

6. Lee, J. (2009). Universals and specifics of math self-concept, math self-efficacy, and math anxiety across 41 PISA 2003 participating countries. Learning and individual differences, 19(3), 355-365.

7. Maloney, E. A., Ramirez, G., Gunderson, E. A., Levine, S. C., \&Beilock, S. L. (2015). Intergenerational Effects of Parents' Math Anxiety on Children's Math Achievement and Anxiety. Psychological Science, 26(9), 1480-1488. https://doi.org/10.1177/0956797615592630

8. Norwood, K. S. (1994). The Effect of Instructional Approach on Mathematics Anxiety and Achievement. School Science and Mathematics, 94(5), 248-254. https://doi.org/10.1111/j.1949-8594.1994.tb15665.x

9. OECD. (2013). PISA 2012 results. Volume III. [Paris]: OECD.

10. Pérez Tyteca, P. (2012). La ansiedad matemática como centro de un modelo causal predictivo de la elección de carreras. Universidad de Granada.

11. Ramirez, G., Chang, H., Maloney, E. A., Levine, S. C., \&Beilock, S. L. (2016). On the relationship between math anxiety and math achievement in early elementary school: The role of problem solving strategies. Journal of Experimental Child Psychology, 141, 83-100. https://doi.org/10.1016/j.jecp.2015.07.014

12. Smith, T. E. (1989). Mother-Father Differences in Parental Influence on School Grades and Educational Goals. Sociological Inquiry, 59(1), 88-98. https://doi.org/10.1111/j.1475-682X.1989.tb01082.x

13. Unesco. (1976). International standard classification of education - ISCED -. Paris: Unesco.

14. Wood, E. F. (1988). Math Anxiety and Elementary Teachers: What Does Research Tell Us? For the Learning of Mathematics, 8(1), 8-13. 